\title{
Translation Courses at Qassim University, Saudi Arabia: A Study of Existing Problems and Possible Solutions
}

\author{
Arif Ahmed Mohammed Hassan Al-Ahdal, Fahad Saleh Suleiman Alfallaj \\ Methnab, Qassim University, Saudi Arabia \\ Salmeen Abdulrahman Abdullah Al-Awaid \\ ELC, Jazan University, Saudi Arabia \\ Nisreen Juma'a Hamed Al-Mashaqba \\ Methnab, Qassim University, Saudi Arabia
}

\begin{abstract}
Studies tell us that human beings lived in groups, and each group developed its own mores, customs, conventions and dialect for interaction; languages evolved out of dialects and as need to communicate among members more effectively. Pronunciation was peculiar to each dialect. Centuries later, need was felt to communicate across many groups. This was the time when someone learnt different languages and dialects, and functioned as intermediary for communicating ideas, seeking cooperation and sharing experiences. In the modern world, therefore, no one can deny that translation is as important in human communication as the language itself. There has been genuine desire from the ancient time and it continues until now to integrate human communities into human society with the aim of leading peaceful and satisfied life, devoid of any strife and opposition, based purely on humane consideration and human values. So, we find that there have been debates about translation methods as language is vehicle for sharing and exchanging ideas, feelings and emotions; in fact, language is clothing of thought and ideas and creating understanding. Techniques for translation varied with individuals: Some preferred literal translation while others grasped the intrinsic meaning in a text and presented the same in another language. Whatever the method, one has to keep in mind that behind a language there is millennia of cultural ethos as well as a fine weave of political, economic, and social practices. This study sheds light on the problems of Translation Courses at Qassim University, Saudi Arabia at the level of both execution and perception and puts forth some suggestions and recommendations that would certainly come in handy for all concerned.
\end{abstract}

Keywords: translation, communication, translation theories, translation techniques, cultural awareness

\section{Introduction}

The current study looks at the learning objectives and teaching outcomes of translation as taught in the

Arif Ahmed Mohammed Hassan Al-Ahdal, associate professor, Ph.D., College of Science and Arts, Methnab, Qassim University, Saudi Arabia.

FahadSaleh Suleiman Alfallaj, associate professor, Ph.D., College of Science and Arts, Methnab, Qassim University, Saudi Arabia.

Salmeen Abdulrahman Abdullah Al-Awaid, assistant professor, Ph.D., ELC, Jazan University, Saudi Arabia.

Nisreen Juma'a Hamed Al-Mashaqba, assistant professor, Ph.D., College of Science and Arts, Methnab, Qassim University, Saudi Arabia. 
English department at Qassim University and whether the output in the form of skill matches the needs of Saudi community in its multifarious functions, activities, professions, and in Saudi Arabia's international socio-political and economic relations. It is believed that translation methods are taught without specific aims but only because the translation courses or lessons have traditionally been a component in the BA (Bachelor of Arts) curriculums. This, consequently, means that these courses do not claim to train the learners as professional translators. This study is a humble effort to highlight that translation courses in Qassim University having had only academic objectives and not professional goals. It is an aim of this study to present a new road-map to enhance the level of the current translation courses.

Undoubtedly, translation is a necessary gateway for creating understanding in others about one civilization in all its dimensions. Educational institutions and universities are obviously greatly interested in preparing and offering well-designed courses of translation with the aim of training graduate students to become competent and efficient translators. For this, it is not only language proficiency that is required but also an understanding of the facts and socio-cultural background of different societies for correct and unambiguous translation since mistakes in translations may lead to misunderstandings, rather disasters. That is to say that translation error on the job may lead to unexpected or undesired outcomes creating disastrous consequences. Erroneous translations of chemical tests can, at times, even lead to poisoning that can be fatal or cause disastrous explosion. Similarly, justice may be defeated and losses incurred in lawsuits where texts are wrongly interpreted in another language. Worse still, think of the international repercussions if an interpreter should poorly translate the well-meant words of a leader causing irreversible damage of reputation and relations.

At Qassim University, the teachers and planners do realise the significant place of the translation courses in BA, yet the objectives of these courses have either not been given the desired foresight or not properly understood, or found difficult to achieve for whatever reasons. It is observed while interacting with the English department faculty and administrators that the course descriptions do proclaim that the aim of the translation course is to introduce the translation theory to the students to understand the methods and approaches and train them as competent translators to and fro from Arabic to English. It has come to the fore during informal discussions with the teachers of translation that the training for translation leaves much scope for improvement of the course and approach thereto to achieve the course goals.

\section{Current Literature}

Brief History-an Overview of what Translation Studies mean: Compared to the conventional courses, translation studies was born as an academic subject just 50 years ago. Earlier to that time, it was a tool in language teaching, thus having a secondary status. Between 1950s and 1960s, Translation as a subject became more scientific and systematic. There was a mainly linguistic approach to translation. Examples are: Vinay and Darbelnet (1958); Catford (1965); and Eugene Nida towards a scientific; Leipzig School for Transparency, etc.

Let us present a review of a few translation studies. James S. Holmes (1972) conducted a study with the title, "The name and nature of Studies" during 1924-1986. This was, in fact, a paper presented in Copenhagen in 1972 at the Translation section of the third International Congress of Applied Linguistics, held under the title "Founding Statement for the Field" quoted by Gentzler in 1992. Holmes declared that the decade 1950-1959 had ushered in a revolution in Translation Studies. According to Holmes there were three obstacles to the further development of the discipline: (1) Scholars and researchers spread out in different fields; (2) lack of common channels of communication; (3) this field was perceived as being too trivial for research. 
Holmes has suggested "Translation Studies (TS)" as the name English that best suits this field. He added that this term would avoid much confusion and misunderstanding which, otherwise, would persist. He also suggested that there should be channels that enabled reach to the scholars undertaking studies in the field, irrespective of their background. He opined that Translation Studies (TS) could be categorized into two main research areas-"Pure" and "Applied". He asserted that descriptive and theoretical translations are the two goals of TS. The former (Descriptive Translation Studies) aims at describing phenomena of translating process, translation as products and manifest as work experiences. The latter (Translation Theory) seeks to establish general principles for enabling the experiencing/phenomena to be explained and predicted. Among the many studies conducted by James S. Holmes, the work entitled "The Name and Nature of Translation Studies" (1972) is especially significant. This pioneering work provided a strong scheme that brought together and established a connection between the components necessary for translation studies. His contribution is considered seminal, effective, and stimulating. His work is historical and a major step forwards to clear the hazy approach till then followed in this area of judging translations. Alongside, Gideon Toury (1995, p. 10) made remarkable contribution to Translation Studies. Descriptive Translation Studies (DTS) focused on three distinct areas: Product (Synchronic and Diachronic), Function (Translation Sociology or Socio-translation Studies), and Process (Psychology of Translation or Psycho-translation Studies).

\section{Background of Translation Studies at Qassim University}

While surveying the current situation of translation teaching at the undergraduate level in the Saudi universities, Qassim University being no exception, we find that the situation is non-too-comfortable: It is marked by some unhappy features:

It is observed that translation courses at the undergraduate level are obligatory in all departments of English, and so, there is no escape from them. However, what is actually offered is quite arbitrary in content and scope with no proper approach for achieving the objective with the desired sharp focus. Further, the approach to teaching and the course content are almost solely a derivative of teacher initiative. It is no exaggeration to say that the English Translation courses are not viewed in wider context but treated as an unavoidable formality.

Sadly, most of the teachers engaged in teaching translation at the University do not have the requisite qualification for it. A large number of them are post-graduates in English Literature or Linguistics from the local or external universities. Assuming that teaching of English language or English Literature is different from teaching of Translation, any teacher who shows an inclination to teach translation is asked to take it up because in the current scenario there are no specific eligibility requirements on the part of teachers. This arbitrariness takes its toll in the Translation classroom.

We would like to reiterate here, that as far as teaching approaches are concerned, it is certain that an arbitrary approach cannot serve as a reliable and sound base for teaching translation; it should rather adopt and follow a scientific and systematic approach to achieve its goals. Those arbitrarily assigned teachers in English departments for teaching Translation frustrate all academic efforts. Students undergoing such specialised courses should be able to translate efficiently if and when offered a translator's job, which is not the case.

It also came to light that most of the translation teachers have not been trained in teaching translation from Arabic to English and vice-versa. Besides, coordinated and concerted effort is missing among the translation teaching teachers. This mars the efficacy and efficiency of the course delivery. Esprit de corps is not confined 
to management; it extends to all human activities for harnessing individuals' energy with synergy-effect.

There is need for imparting continuous training (not one-shot training) programmes for University translation teachers; absence of it has contributed to the current avoidable status. To improve this condition, the teachers may embark upon self-development: They may take personal initiatives and train themselves, as they sometimes do. However, even with this personal initiative, their efforts come to naught owing to work overload, teaching a variety of courses at various levels which requires as much time and effort to prepare for the classes. Consequently, no department so far has ever produced a textbook on translation or even a guide for translation teaching or a manual for translators.

Without an exception, teaching of translation courses falls on the English departments that do not have adequate training for it, are constantly bogged by time deficit, and are largely at sea for dearth of teaching materials and pedagogy. The result is that translation courses are taught without any scientific system, making them purposeless for end use.

\section{Methodology of Teaching Currently in Use by Translation Teachers}

The practice currently followed by some Translation teachers at Qassim University involves selecting their own materials. This is done at individual level and there is little or no coordination among them. Clear cut training benchmarks are absent in the translation courses. There are many of the teachers who would not bother even to motivate the students to go in for the texts that they carry to the classroom. Such texts used by the teachers are either pre-translated or mostly sourced as translated texts; they serve as ready material for use by the teacher. This being so, there is a limited interaction in the classroom. It is in the nature of asking a student a question-Tell me what this mean and the ready-made answer is in the teacher's hand, with no initiative to explain, interpret, or rationalize. Stated in other words, we can say that there is no clear teaching approach adopted by the teacher concerned. In many cases, students cannot develop their reasoning, skill, and understanding; it is just cramming and repeating without creating understanding. They grapple a trial-and-error task, keep trying to guess what the teacher has in mind, or depend on their lecture notes. The result is that they end up studying texts and the translation thereof but nothing of the process of translation. The students' tests also reflect that they rarely upgrade their language proficiency. What happens next is a matter of simple guess: Some students get frustrated being dissatisfied with the traditional approach adopted during the course, while others develop the misconception that this is all there is to translation.

Testing and evaluating students' performance: As a consequence of the status of translation teaching mentioned above, coupled with the profile of translation teachers, nature and types of teaching materials used, and methodology adopted for translation teaching, testing and evaluating the students' performance involves the translation of a text from English into Arabic and/or vice versa. This is the conventional testing methodology. However, this is certainly not what translation is all about. Rather it ought to have been a well-graded skill building programme. Evaluation of these tests is, therefore, highly subjective. The teachers are unanimous in asserting that students' performance is very poor. The teachers end up marking language errors and not translation drawbacks.

\section{Conclusion of Current Literature and Environment}

The foregoing short description takes us to believe that Qassim University cannot train students to make them efficient translators by imparting the courses of translation because of the following reasons: 
(1) The teachers are untrained without having received any formal training in the teaching of translation;

(2) There is ad hoc treatment given to all activities and exercises in regard to content selection and teaching methodology adopted in Qassim University;

(3) The outcomes (objectives) of the course are not clear to the teachers and students alike;

(4) Evaluation is meaningless given the three points stated above.

\section{Objectives of the Study}

The present study aims at outlining a new, more realistic and explicit roadmap for the courses of translation at the Qassim University, Kingdom of Saudi Arabia. The specific objectives are the following:

(1) To examine the contents of the present course of teaching English Translation in Department of English at Qassim University to find out the relevance towards creating skills of translation from Arabic to English and vice-versa;

(2) To suggest suitable curriculum/syllabus to recast the present English Translation course at the Department of English, Qassim University to create competent translators/interpreters in English with sensibility to language (to both mother tongue and foreign language), reading comprehension ability, and the ability to translate and interpret various texts;

(3) To suggest a different approach to teach English Translation to create translators as professionals, able to write the target language as a means of communication.

\section{Research Questions}

(1) Is the preset course of English Translation offered by Qassim University to transform students into professional translators and interpreters adequate in content and approach?

(2) Do the students of English Translation course at Qassim University feel competent to translate various texts into English and vice-versa?

(3) Are the students of English Translation course at Qassim University able to understand and apply translation models?

(4) Are the students proficient in reading comprehension in English as foreign language?

(5) Are the students equally sensitive to both the mother tongue and the target language and possess due competence to write proficiently in the target language?

\section{Methodology}

This is an empirical study undertaken by gathering primary data from translation teachers and students at the University. Eight teachers and 40 students in four different departments were requested to respond to questionnaires that sought their perception vis-à-vis the course. The exercise was taken up simultaneously to reduce chances of data dilution due to peer influence.

Each of these questionnaires (see appendices A \& B) carried 10 multiple choice questions. Male and female respondents were equal in number, i.e., four teachers and 20 students were males and an equal number were females. The questions attempted to explore their overall attitude towards the course on dimensions like its content, the teaching methods adopted by the teaching faculty, the efficiency of the translation teachers, and the overall translation program offered for University students in the Departments of English language. As for the teachers, we tried to find out their reasons for taking up the teaching of translation, their comfort level in the 
classroom, and professional satisfaction among other things. Some of the respondents even expressed their individual opinions beyond the scope of the questionnaires, but these have not been incorporated in the current study for want of reliability and validity.

\section{Analyses and Observations}

We now present the teachers' responses with graphical representations and interpretation:

The demographic data showed that the sample was uniform with equal representation for males and females, falling in the common age bracket of 35-40 years, possessing at least a Ph.D. degree and having more than five years of teaching experience.

Q5. What prompted you to volunteer for teaching translation?

Asked about the reason for choosing to teach translation, seven out of eight teachers cited "no specific reason" while one opted for "greater comfort level". Clearly, the teachers are not motivated per se to teach the course and take it as just another "duty" to be fulfilled as part of the job.

Q6. How many hours have you spent so far in training/educating yourself for teaching translation?

Teaching is, by its very nature, a learning experience for the teachers, but all of the respondents clearly stated that they have spent less than 10 hours on educating themselves to teach the Translation course. The result is all the more shocking as it clearly shows that they do not even engage in self-development on a day to day basis to update themselves with the latest happenings/developments in the field.

Q7. How would you rate your professional ability in the translation classroom?

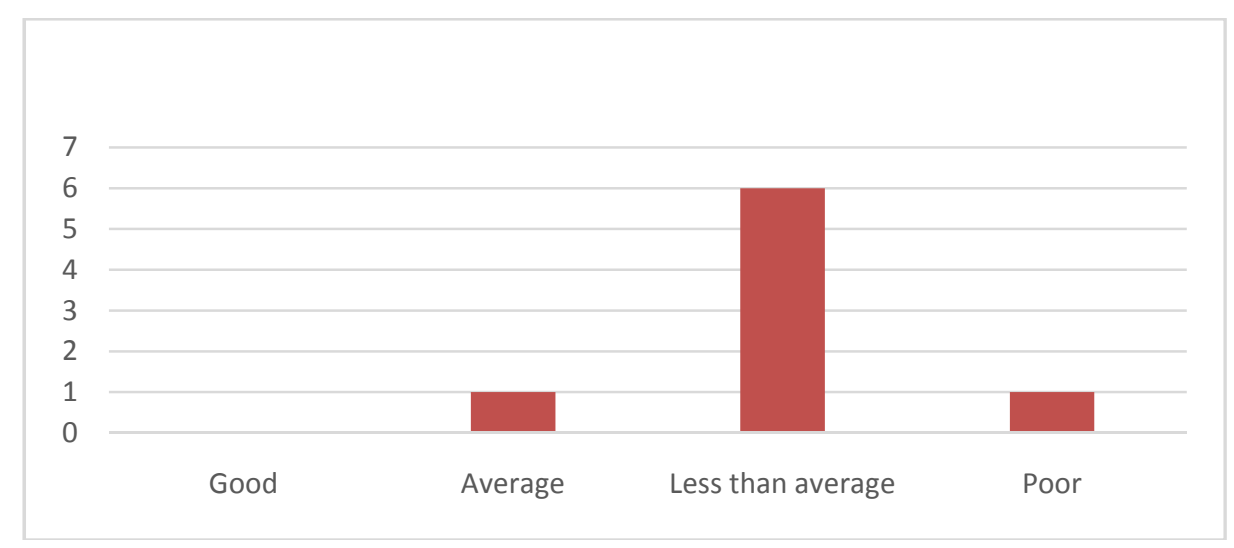

Q8. According to you, the translation course is which of these?

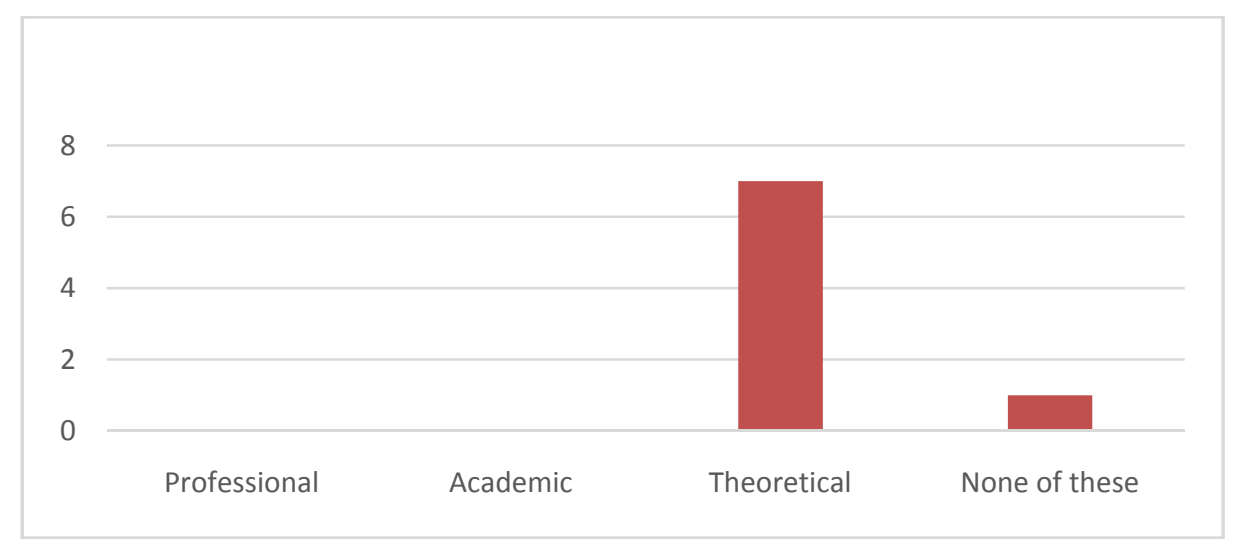


Six out of eight respondents among the teachers, however, are realistic enough to rate their teaching output as less than average even as they believe that this is a theoretical course.

Q9. As "Professional Translators", where would you place the majority of your students on course completion?

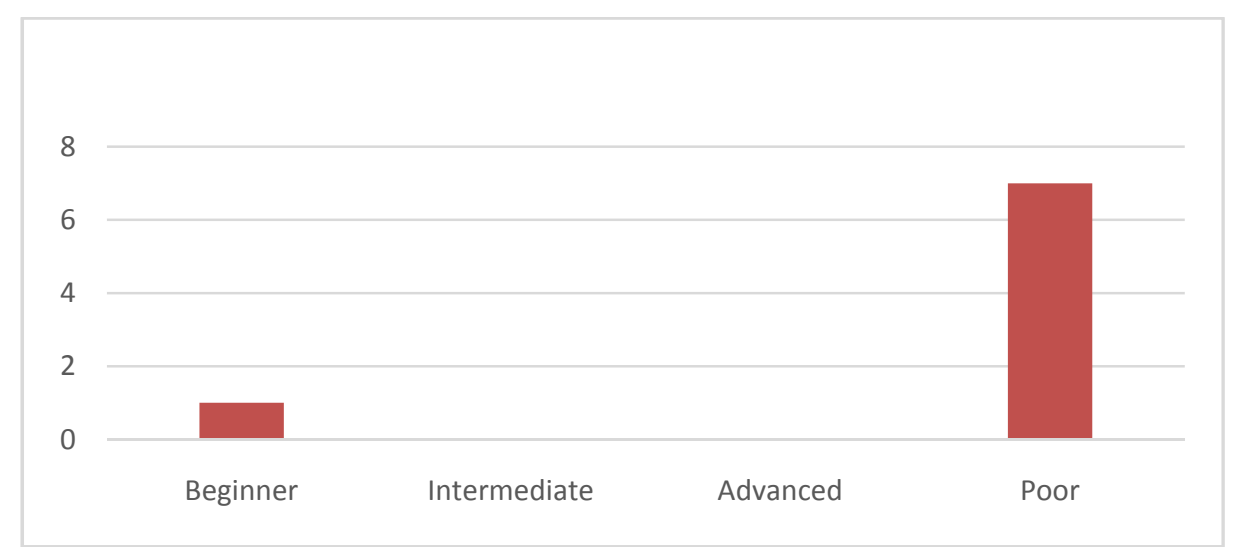

Seven out of eight respondents rate their students as "Poor" translators.

Q10. How would you rate your status as a Translation teacher?

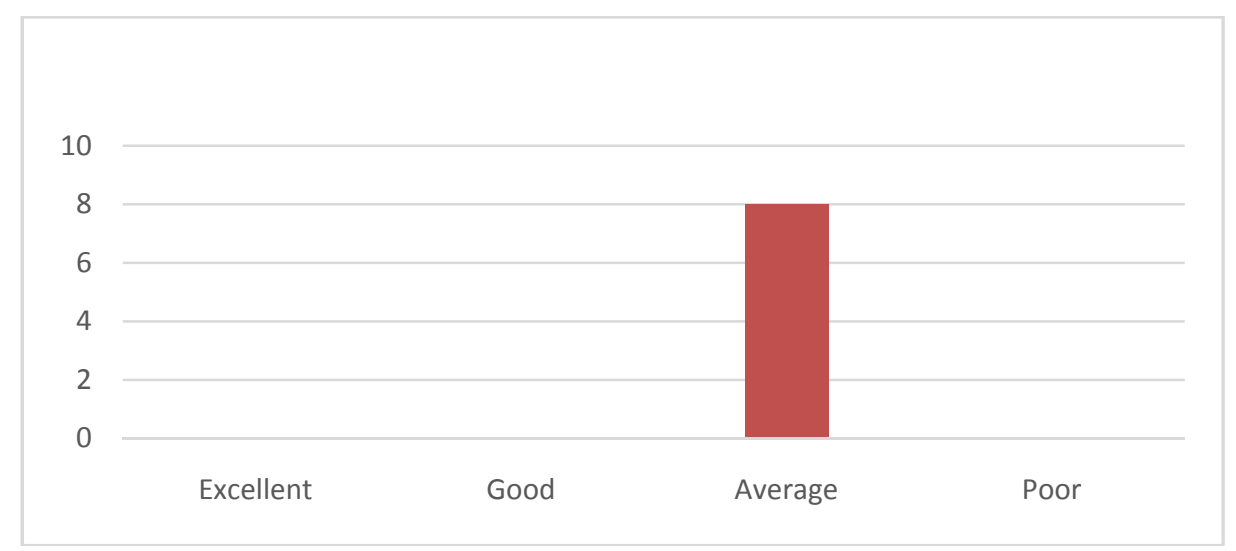

All of the eight rate themselves as "average" teachers.

The findings of the students' Questionnaire are graphically summarized as under:

Q3. What do you think the objective of training students in translation is?

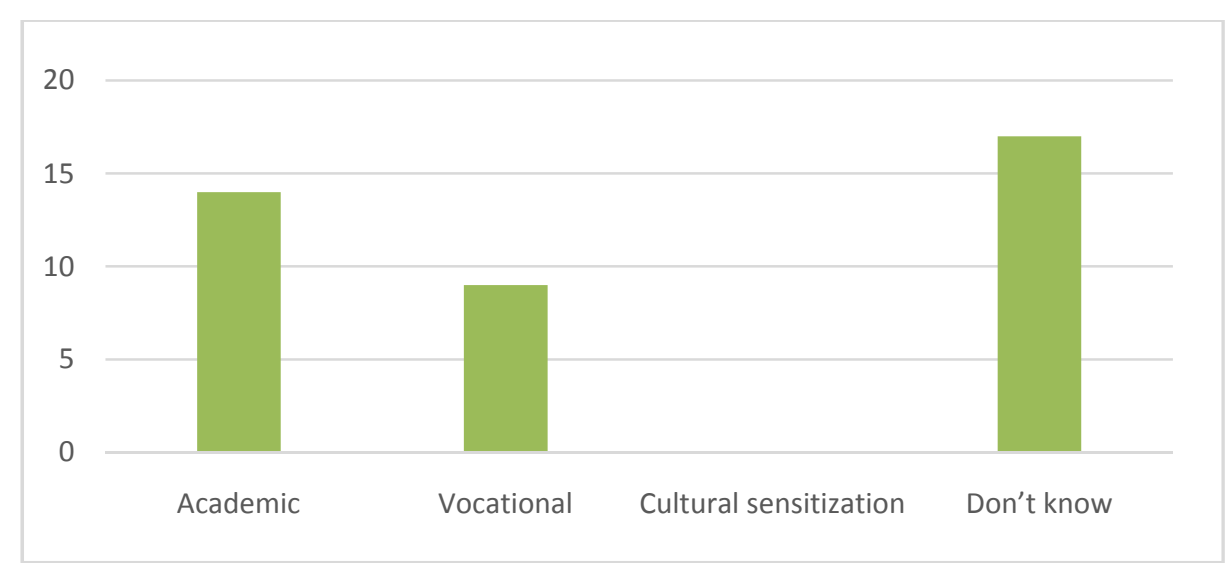


Q4. Please rate the content of the Translation Course.

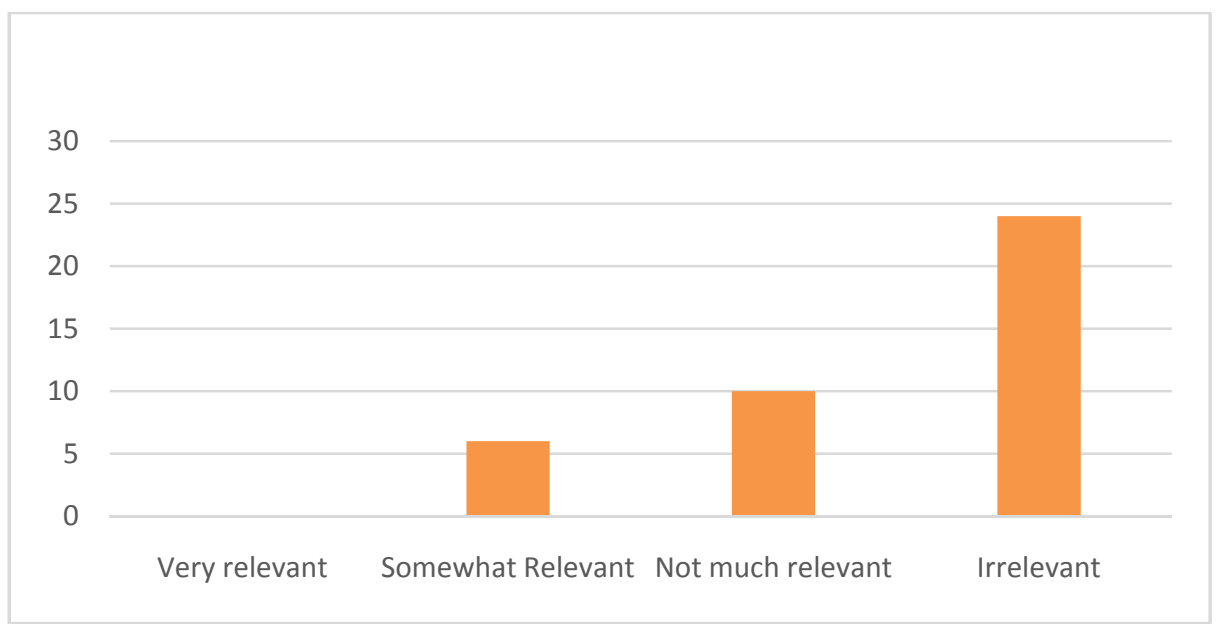

Q5. How equipped are your teachers to deal with the course?

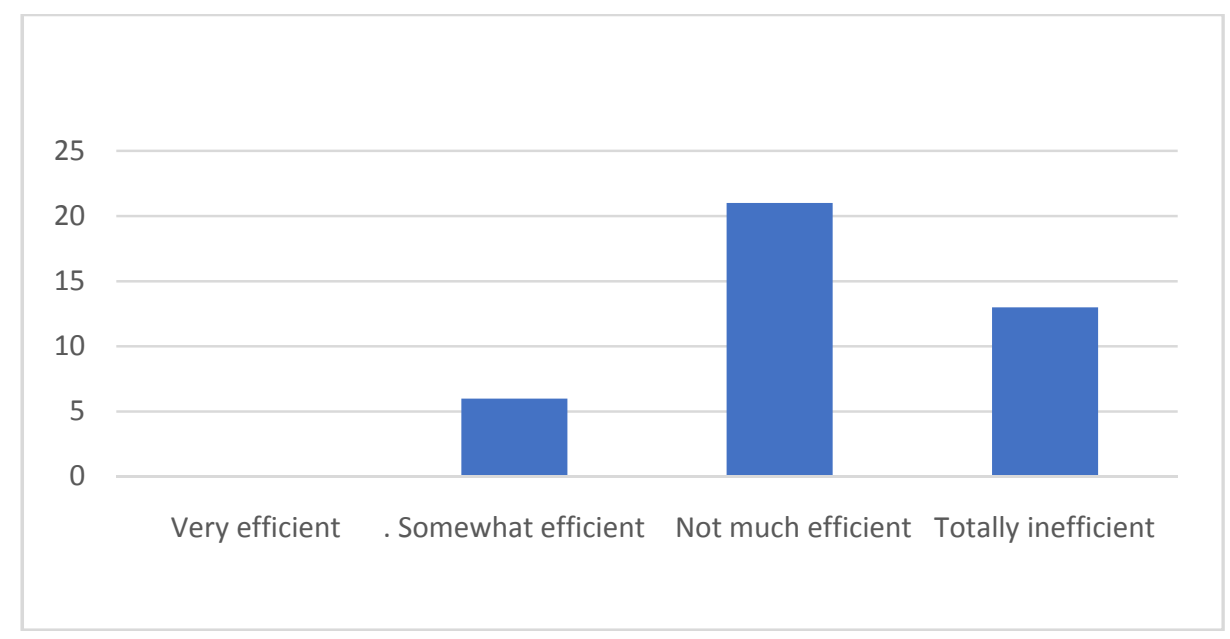

Q6. By taking the course, how proficient do you feel you would be as a translator?

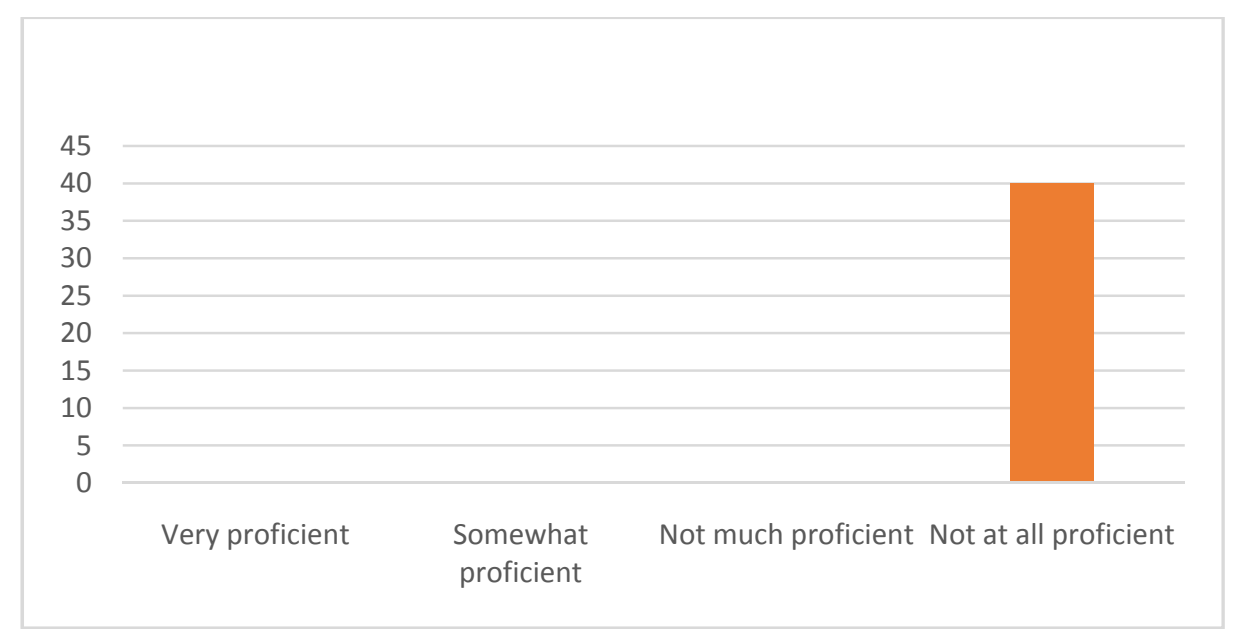


Q7. Once the course is over, how do you see the chances of your landing a translator's job?

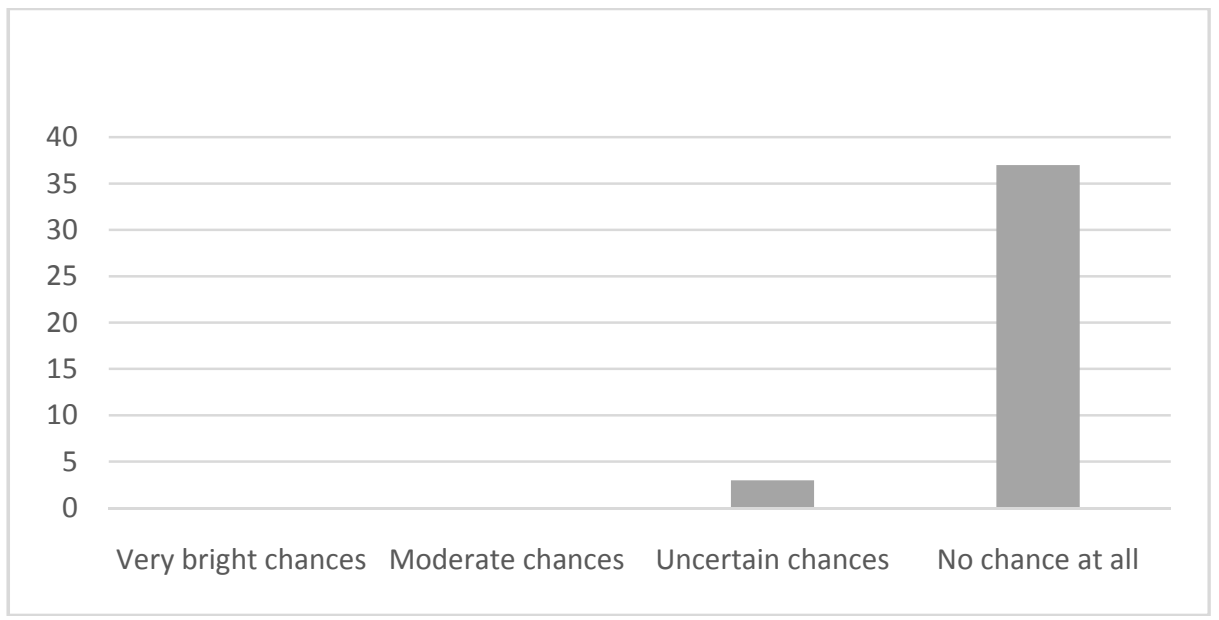

Q8. Which is the most frequently used method the teacher uses to teach translation to your class?

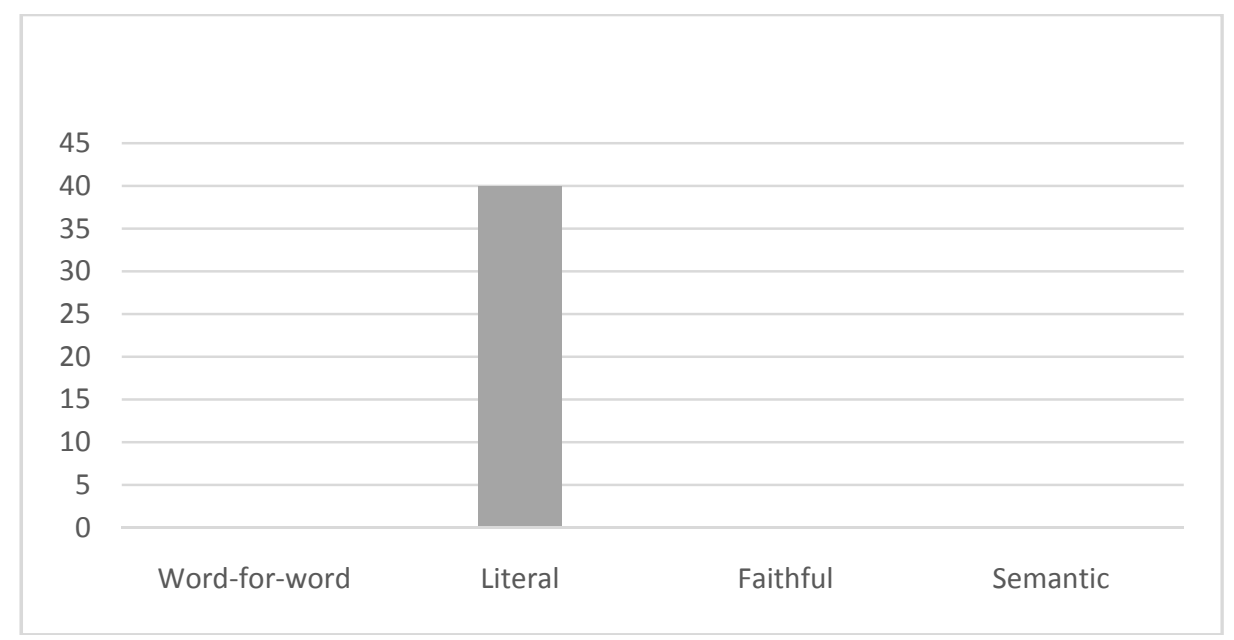

Q9. What, according to you, needs be done to improve the employability of Translation students?

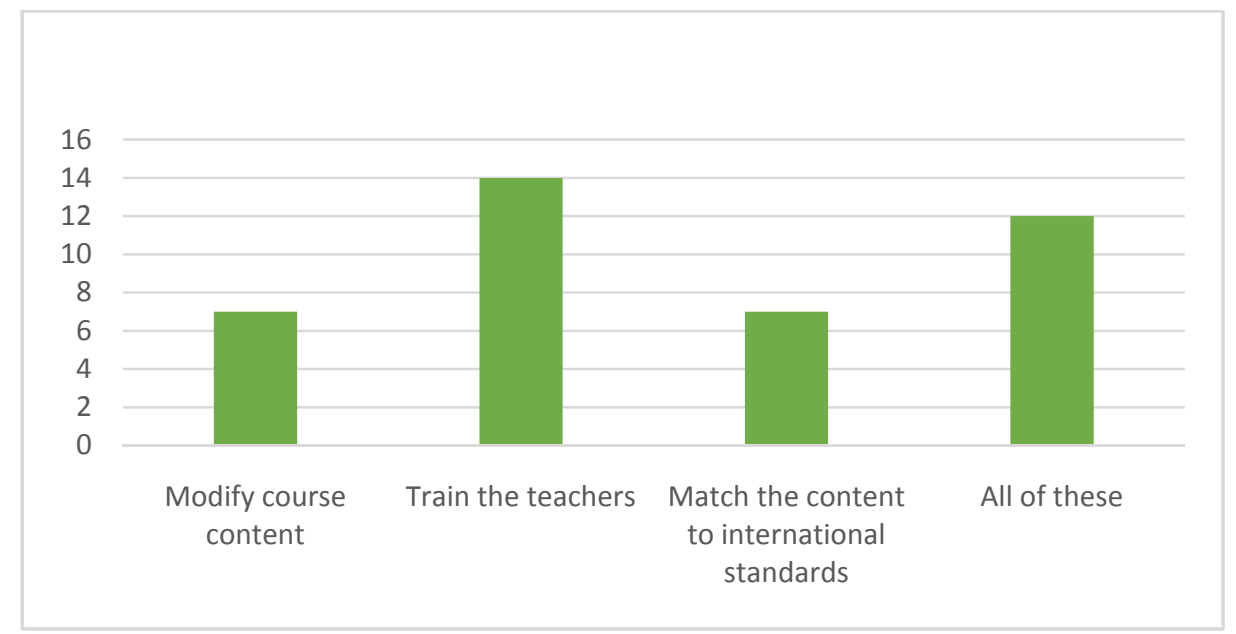


Q10. How do you rate the Translation programme at the University?

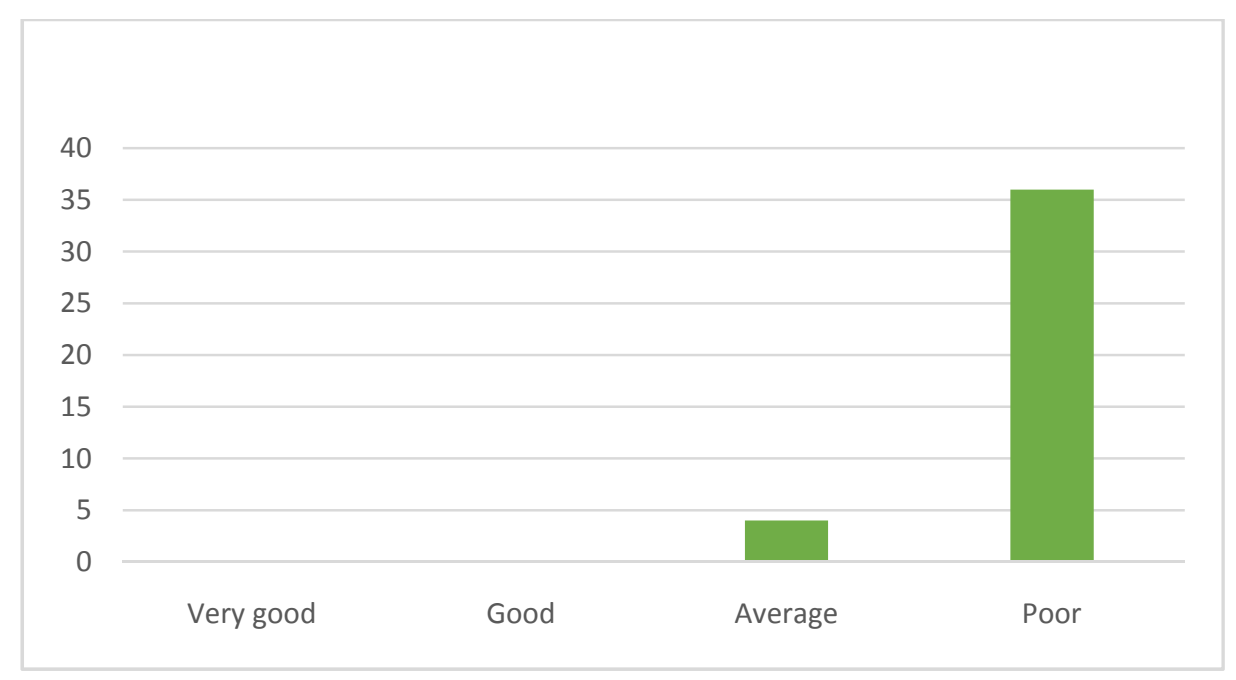

The opinion formed is that there is an urgent need to review the objectives of the University's Translation course and decide soon with specificity its teaching methods on the understanding that translation is taught at English and/or allied departments not for a primary academic purpose but is clearly a professional course with vocation related expectations. By doing so and implementing with commitment and earnestness shall the Saudi people be benefited as there would be professional translators/interpreters available to answer the emerging needs for such professionalism in view of Globalisation process for ushering in free trade regime. By doing so, the Saudi people/government can capitalize on the prospective progress to be achieved in academic years to come.

There are various definitions of "Translation". However, all of these state clearly that "Translation" is taken to be both a science and craft. Newmark (1998a, p. 7) describes translation as an art that aims to produce a message that was delivered in one language, in another. The problems of the Arab students are rather peculiar: They learn English as a foreign language, and hence, translation tutors should be aware that they are expected to teach both the English language and the craft of translation. Further, that at the university, much like any other discipline, Translation is to be taught as an academic calling investing most pedagogical energy in upgrading students' proficiency in the source as well as the target language. Teaching the craft of translation should, at least at this point, be left to specialized establishments, where training is professional rather than academic.

\section{Strategy and Methods for Teaching Translation: A Roadmap}

The objectives stated here must be kept in view while selecting texts for translation, the degree of text difficulty with difficulties centred around these mantic, stylistic, syntactic, or cultural aspects, and the topics should broadly cover political, cultural, political, economic, and literary pieces.

The students should be encouraged to read the text first to grasp the general connotational meaning. The second reading should target the translation and finding out problems.

They should be encouraged to mark the difficult terms and deduce their meaning using suitable translation procedures.

The teacher divides the text into segments so that each student in a group gets to do one. The division will 
be done keeping in mind the degree of difficulty and the length of the text involved. These segments may be short like paragraphs or columns, or lengthy pages, or even whole chapters. These segments are to be rotated so that every student gets to do a new segment every time.

It may transpire that the topic is already easy and familiar to the student. In that case, they can do a preliminary translation right away. However, Newmark (1995a) warned that students sometimes transfer SL units of translation to TL units of translation (one-to-one translation).

Once the "one-to-o"" version is completed, the students do a second version of their own translation.

This will take the students to this final stage and ensure to follow the same correlative order of the SL text: With the original text in front of each of them, each student reads out her/his own version of the translated text. All other students and the teacher follow each text attentively while reading goes on. For monitoring, everybody should feel free to stop the reading of a text or repetition of a segment to add comments, suggestions, questions, contributions, etc. However, the students have to be ready with reasons for their particular translation.

The students are encouraged to take notes and discuss the contributions and comments resulting from this analytical reading of each different version proposed. They are assisted by the teacher also to discuss the reasons that were taken into account for choosing each analyzed criterion. This is a metacognitive activity. According to Kussmaul (1995), "The ability to discuss translations in an objective way is central to a translator's competence" (p. 98).

Finally the students hand in the final version of their revised and post-edited segments, which has already been improved in the light of the whole text. For reasons of uniformity, the work must be typed, double-spaced, and paged according to the original.

Now in the final stage, the teacher revises the text, gives formative evaluation, and makes comments, emphasizing findings and highlighting analysis failures and weaknesses in the process.

This methodology sees the teacher's role as that of a facilitator of the translation task. The lion's share of the translation process is executed by the students themselves, either collectively in a group, in pairs, or individually. It is observed that to do the process of translation efficiently, students could consult all possible information sources including the traditional written forms, the "live" sources, or informants.

\section{Students' Role in Translation Teaching/Learning Process}

As the process of translation should run smoothly, the learner-students are expected to meet the following base conditions:

(1) Strong linguistic grounding in the two languages, apart from knowledge of the socio-cultural spectrum. The foundation courses before admitting students to translation courses should be in reading, writing, and syntax. This necessitates the teachers' effective teaching and their accurateness in the evaluation of the students' performance in the exams in general and more specifically in the first two years of the BA Programme;

(2) The students must be highly proficient and competent in reading. They should also be trained in an adequate use of translation procedures and strategies;

(3) The students must be familiar with management of documentation sources;

(4) The students should be motivated to develop to have initiative, creativity, honesty, perseverance, and accuracy, all of which will ensure they do full justice to a text;

(5) The students should be encouraged to develop analytical ability to be their own judge; 
(6) Finally, the students should be aware of software translation facilities and be computer savvy.

According to Orellana (1994) as quoted in Sofer (2011), it is important for a translator to understand the original text. They will do so efficiently if they have wide general knowledge coupled with capacity to handle the vocabulary of the topic in SL as well as in the TL. In addition, they should have the capacity to produce well written Arabic translation version of the SL.

\section{Teachers' Role in Process of Translation Teaching}

Without educators, nothing worthwhile would be achieved. Therefore, the educators should have the following characteristics:

Educators must be highly competent communicatively and linguistically. According to Bell (1995, p. 42), this is characterized by such a level of language ability in the translator as allows him/her to not only produce the discourse in the target language but also such a one as agrees with the social milieu.

This consists of four areas of knowledge and skills:

(1) Good knowledge of the rules of the code covering the whole gamut of vocabulary, word formation, pronunciation, spelling, and sentence structure;

(2) Sociolinguistic competence to place utterances in the appropriate context as we know that language is a social entity;

(3) Discourse competence enables the translator to combine the form and meaning of the text to achieve unified spoken or written texts in different genres;

(4) Strategic competence which is important for better communication, compensating communication breakdowns in real time communication;

(5) Responsibility for facilitating translation learning process. Therefore, the educators must be well versed with the structure of SL and the TL, translation theory, causes of negative interference, and methodology of teaching translation;

(6) According to Bell (1994), prefect knowledge of the process of the translation is necessary. Interest in reading all types of texts is pre-requisite for acquiring proficiency in "Translation" process in addition to having enough capacity of appreciating what is read;

(7) The teachers should be highly proficient in communication.

(8) Teachers should be aware of terminological and language resources like monolingual and bilingual dictionaries, specialized dictionaries, encyclopedias, glossaries, and various texts on translation theory and practice and have free access to international data processing nets, informants, experts, and other sources of translation;

(9) Educators must master all types of equivalence. This means that teachers of translation must be highly aware of the following points in equivalence:

(a) Grammatical equivalence: Languages evolve in differentiated environment and become store-houses of cultural and traditional values. Consequently, a language has its unique grammar. This fact may pose some problems in terms of finding a direct correspondence for texts in the TL. According to Baker (1992), such unavoidable differences may change remarkably the information or message. These, in turn, may lead the translator either to add or to drop information in the TL. Baker focuses on number, tense, voice, person, and gender as grammatical devices which, according to him, may cause problem in translation;

(b) Textual equivalence: Texture in translation has its importance. It guides the comprehension and 
analysis of the ST and helps the translator produce a cohesive and coherent translated text. In this, three factors should be taken into account, the target audience, the purpose of translation, and the text type;

(c) Pragmatic equivalence: It refers to the translator's task of bringing out the implied meanings in the text.

(10) Teachers must be updated on the pedagogical options for teaching translation;

(11) Teachers of translation must be competent enough to employ one or more of these methods, as appropriate, when taking translation classes.

According to Newmark (1998b), these methods are as under:

(1) Word-for-word translation: This leaves the SL word order untouched but translates the individual words by substituting the most commonly used meanings. The contextual meaning is not given primacy;

(2) Literal translation: This method still leaves the words to be again substituted by the closest TL equivalents, but the sentence structure is also altered, adopting the nearest available in TL. Once again, the contextual meaning is not given primacy;

(3) Faithful translation: This goes closest to the intended meaning of the original text/words/phrases by substituting the words as well as the appropriate TL sentence structure;

(4) Semantic translation: According to Wikipedia, this is quite close to "faithful translation". The process of this translation type is using semantic information to aid in the translation of data in one representation or data mode to another representation or date mode;

(5) Adaption: As suggested by the name, it is the freest form of translation and is used mainly for fictional writing and poetry. The themes, characters, and plots are usually preserved. The SL culture is converted to the TL culture and the text is rewritten. This is stated in Wikipedia (http://en.wikipedia.org/wiki/Semantic_translation);

(6) Free translation: This merely grasps at the central themes of the SL and reproduces them in the TL text without the style, form, or content of the original;

(7) Idiomatic translation: This takes off from Free Translation but adopts TL specific idioms and colloquial elements thus distorting the finer meanings of the SL text;

(8) Communicative translation: A method most suited for communication, and this produces the exact contextual meaning in the TL in terms of both content and language (1998b, pp. 45-47).

Finally, the assessment criteria must be very clear to the translation teacher even before they embark upon teaching the course.

With training of the translation teachers in these methods, we may be hopeful of enabling the students of translation to develop sensitivity to the languages they deal with and become competent and proficient translators.

\section{Conclusion}

This leads us to conclude that the translation teachers and departments at Quasim University need to clearly concretize their objectives. This will provide a direction in which to work to the teachers as well as the learners. Professionalism is crucial to such translation teaching programmes. This would ensure that translation courses are not treated as merely academic courses but vocation related courses as the aim. The teaching must produce efficient translators. This should be the primary objective. This study suggests a review of the course content, pedagogies, and developments the world over in the field of translation. With a world moving fast towards global integration taking the route of economy and thereafter social, cultural, and political synthesis 
and integration will be the next logical steps. In such an emerging scenario, translators and interpreters will be in unavoidably great demand, and therefore, they should be developed as competent, capable, and efficient ones in the interest of the country they belong to, the society at large, and their individual vocational success.

\section{Recommendations}

We strongly recommend the following measures:

(1) Design translation courses so as to address the emerging needs of the numerous quasi-professionals engaged in the translation and interpretation industry, working with the "immigrating" languages;

(2) Translation courses should extend their scope beyond the languages prominent in the languages of the American continent and European Union;

(3) In principle, the course should be as streamlined to industry requirements as possible and the main beneficiaries should sponsor it;

(4) It should seek to ensure cross-border recognition of qualifications and certification;

(5) As we expect our graduates to find employment in other parts of the world, the course should be designed to match the certification systems followed in the United States, Canada, Australia, and China, which are also the leading economies of the world;

(6) It should synchronise with the needs of the employers;

(7) The assessment criteria for these learners should be such as is respected and recognized internationally;

(8) Till examination and grading systems as recommended above are designed and implemented, the University should be wary of granting automatic professional certification on the basis of academic degrees alone.

\section{References}

Baker, M. (1992). In other words. A course book on translation. London: Routledge.

Bell, R. T. (1994). Translation and translating. London: Longman Group UK Ltd.

Bell, R. T. (1995). Translation and translating: Theory and practice. London: Longman.

Catford, J. C. (1965). A linguistic theory of translation: An essay on applied linguistics. London: Oxford University Press.

Holmes, J. S. (1972). Paper presented in The Translation Section of the Third International Congress of Applied Linguistics, Copenhagen.

Kussumaul, P. (1995). Training the translator. Amsterdam, Netherlands: John Benjamins Publishing Co.

Newmark, P. (1995a). Manual de traduccion. Hertfordshire: Prentice Hall International (UK) Ltd. Ediciones Catedra, S.A.

Newmark, P. (1995b). Approaches to translation. Hertfordshire: Prentice Hall.

Newmark, P. (1998 a). A textbook of translating. Hertfordshire: Prentice Hall.

Newmark, P. (1998b). A Textbook of translation. USA: Liberty of Congress Cataloging-in-Publication Data.

Sofer, M. (2011). Translator self training-Spanish: A practical course in technical translation. Rockville: Schreiber Publishing.

Toury, G. (1995). Descriptive translation studies and beyond. Amsterdam and Philadelphia: Benjamins.

United States Department of Labor. (2010). Occupational outlook handbook (11th ed.). Interpreters and translators. Retrieved from http://www.bls.gov

Vinay, J., \& Darbelnet, P. (1995). Comparative stylistics of French and English: A methodology for translation. J. C. Sager and M. J. Hamel (Trans. and Eds.). Amsterdam: Benjamins. 
Appendix A: Teachers' Questionnaire

1. Please mark your gender
a. Male
b. Female

2. In which age bracket would you place yourself
a. $25-30$
b. $30-35$
c. $35-40$
d. beyond 40 years

3. What is your highest educational degree
a. BA
b. MA
c. Ph.D
d. D.Litt

4. What is your total experience teaching translation
a. Below 5 years
b. 5-10 yearrs c. $10-15$ years
d. more than 15 years

5. What prompted you to volunteer for teaching translation
a. Intrinsic interest
b. Professional pressure

c. Greater comfort as compared to teaching of Literature or Language

d. No specific reason

6. How many hours have you spent so far in training/educating yourself for teaching translation
a. $30 \mathrm{hrs}$
b. $50 \mathrm{hrs}$
c. more than $50 \mathrm{hrs}$
d. less than ten hours

7. How would you rate your professional ability in the translation classroom
a. Good
b. Average
c. Less than average
d. Poor

8. According to you, the translation course is which of these
a. Professional
b. Academic
c. Theoretical
d. None of these

9. As "Professional Translators" where would you place the majority of your students on course completion
a. Beginner
b. Intermediate
c. Advanced
d. Poor

10. How would you rate your status as a Translation teacher
a. Excellent
b. Good
c. Average
d. Poor

\section{Appendix B: Students' Questionnaire}

1. Please mark your gender
a. Male
b. Female

2. How many years of University education have you had before you began with the Translation Course
a. Less than two years
b. 3 years
c. 4 years
d. more than 4 years

3. What do you think is the objective of training students in translation
a. Academic
b. Vocational
c. Cultural sensitization
d. Don't know

4. Please rate the content of the Translation Course
a. Very relevant
b. Somewhat Relevant
c. Not much relevant
d. Irrelevant

5. How equipped are your teachers to deal with the course
a. Very efficient
b. Somewhat efficient
c. Not much efficient
d. Totally inefficient

6. By taking the course, how proficient do you feel you would be as a translator
a. Very proficient
b. Somewhat proficient
c. Not much proficient
d. Not at all proficient

7. Once the course is over, how do you see the chances of your landing a translator's job
a. Very bright chances
b. Moderate chances
c. Uncertain chances
d. No chance at all

8. Which is the most frequently used method the teacher uses to teach translation to your class
a. Word-for-word
b. Literal
c. Faithful
d. Semantic 
9. What, according to you, needs be done to improve the employability of Translation students
a. Modify course content
b. Train the teachers
c. Match the content to international standards
d. All of these

10. How do you rate the Translation programme at the University
a. Very good
b. Good
c. Average
d. Poor 